\title{
ABANDONO AFETIVO: UMA ANÁLISE LINGUÍSTICA DISCURSIVA DE APELAÇÃO DO TJRS
}

\author{
AFFECTIVE ABANDONMENT: A DISCURSIVE \\ LINGUISTIC ANALYSIS OF THE TJRS APPEAL
}

Janice Raquel de Lima*

Jussivania de Carvalho Vieira Batista Pereira**

Resumo: Neste trabalho, abordamos a relação interdiscursiva (maneira como um discurso se relaciona com outro discurso) entre duas áreas do conhecimento: Direito e Linguagem. O foco dessa relação está mais especificamente na área de concentração da Análise Crítica do Discurso (ACD), por sua transdisciplinaridade. Assim, pretendemos identificar e analisar os modos como a relação Linguagem e Direito se materializam na prática social do abandono afetivo e como essa prática social é enfrentada pelos julgadores por meio da aplicabilidade das leis. O referencial teórico-metodológico concentra-se, especificamente, na ACD, de Fairclough (2003) significado representacional - e Linguística Sistêmico Funcional de Halliday (2004) - sistema de transitividade. A construção do corpus originou-se de um recurso de Apelação do Tribunal de Justiça do Rio Grande do Sul acerca da indenização por dano moral decorrente de abandono afetivo. Assim, à luz da ACD, buscamos interpretar e refletir sobre as escolhas lexicais utilizadas no julgamento.

Palavras-chave: Direito. Linguagem. Análise crítica do discurso.

ABstract: In this work, we approach the interdiscursive (how the speech relates to another speech) relationship between two areas of knowledge, Law and Language. The focus of this relationship is more specifically in the area of concentration of Critical Discourse Analysis (CDA), due to its transdisciplinary. Thus, we intend to identify and analyze the ways in which the relationship between Language and Law materializes

\footnotetext{
"Advogada, professora universitária, é graduada em Direito e em Secretariado Executivo Trilíngue. Especialista em Direito Processual Civil, Direito do Trabalho e em Didática do Ensino Superior. Possui mestrado em Estudos de Linguagem pelo Programa de Pós-graduação em Estudos de Linguagem, da Universidade Federal de Mato Grosso (UFMT). E-mail: markeslima.adv@hotmail.com.

"Doutoranda do Programa de Pós-Graduação em Estudos de Linguagem da Universidade Federal de Mato Grosso. Possui mestrado em Estudos de Linguagem pelo Programa de Pós-graduação em Estudos de Linguagem, da Universidade Federal de Mato Grosso (UFMT). Bolsista FAPEMAT. E-mail: jussivaniabatista@gmail.com.
} 
in the social practice of emotional abandonment and how this social practice is faced by judges through the applicability of laws. The theoretical-methodological framework focuses specifically on Fairclough's CDA (2003) - representational meaning - and Halliday's Functional Systemic Linguistics (2004) - transitivity system. The construction of the corpus originated from an appeal of the Court of Justice of Rio Grande do Sul on the indemnity for moral damage resulting from emotional abandonment. Thus, in light of the CDA, we seek to interpret and reflect on the lexical choices used in the judgment.

KeYwords: Law; Language; Critical Discourse Analysis.

\section{INTRODUÇão}

A relação Direito e Linguagem no Brasil não está, ainda, consolidada como linha de pesquisa, mas vem caminhando para isso (COLARES, 2014). Podemos citar aqui a Análise Crítica do Discurso (ACD), por exemplo. A ACD não corresponde apenas a uma disciplina no campo da linguística, e sim um método de investigação para compreender o uso da linguagem nas mais diversas práticas sociais, ofertando um suporte científico para o questionamento de problemas sociais que emergem poder por meio da manutenção e transformação de representações, identidades, sistema de crença e conhecimento e relações (CHOULIARAKI; FAIRCLOUGH, 1999; FAIRCLOUGH, 2001, 2003; LEAL, 2009; MAGALHÃES, 2010). Nesse sentido, as articulações das duas áreas científicas - Direito e Linguagem - são, aparentemente, pretenciosas, porém necessárias.

Nosso objetivo consiste em identificar e analisar os modos como a relação Linguagem e Direito se materializa na prática social do abandono afetivo e como essa prática social é enfrentada pelos julgadores por meio da aplicabilidade das leis.

O contexto histórico da relação Direito e Linguagem iniciou-se em meados do século XX como uma nova maneira de estudar as teorias de argumentação jurídica. Com o advento do pós-guerra, houve a necessidade de ultrapassar os métodos da racionalidade instrumental, que orientavam toda a construção do conhecimento científico da época.

Nesse período, Hans Kelsen (1979) elaborou a Teoria Pura do Direito sustentado no positivismo e na forma estruturalista de pensar o direito. Ele é pioneiro nos estudos acerca da construção do Direito enquanto status de ciência moderna, e sua obra influenciou a tradição positivista/racionalista brasileira. Sua teoria pura do Direito baseava-se em elementos objetivos e concretos, pois "segue a reboque as ciências da natureza e exatas" (COLARES, 2010, p. 459).

De acordo com Kelsen (1979), existem fatores externos ao direito e esses não estariam sujeitos a análises dentro do campo das ciências jurídicas. Pensando em um Direito positivado, 
racional, os aspectos econômicos, sociais, psicológicos, políticos deveriam ser ignorados pelos juristas, pois deveriam ser considerados elementos estranhos à área jurídica.

Dessa forma, a maneira positivada de pensar o Direito passou a ser uma explicação plausível para seu afastamento das demais áreas das Ciências Sociais, por acreditar que o Direito tivesse uma linguagem própria, isolada. Entretanto, devido às premissas históricas do pós-guerra, o modelo estruturalista começou, em tese, a desaparecer das academias, dando lugar à exaltação das ciências pelos discursos científicos, contribuindo de forma gradual para o interesse e a exploração das áreas do conhecimento enquanto ciências integradas e não isoladas.

\section{LINGUAGEM: UMA FORMA ATIVA DE INTERPRETAR O DIREITO}

No século XX, o positivismo jurídico, enquanto eixo das discussões científicas, passou a ser questionado pelos filósofos e sociólogos, pois acreditavam que os métodos empregados, estruturalistas, não atendiam às pretensões sociais e que nenhum modelo pré-determinado seria capaz de resolver os anseios coletivos e/ou individuais, abrindo, assim, possíveis caminhos para interpretação do Direito através da Linguagem.

O positivismo jurídico ou juspositivismo é uma corrente filosófica das ciências jurídicas, que procura limitar o Direito apenas àquilo que está posto, efetivado, materializado, objetivado, positivado, ou seja, utiliza-se de método científico pré-ordenado, empirista para estudar e compreender o ramo jurídico (BOBBIO, 1995).

Com a concepção filosófica positivista, o Direito tende a se estruturar como um discurso descritivo sobre fatos sociais. As descrições são externalizadas através das normativas legais, nas quais a linguagem jurídica cumpre apenas o papel de transmitir a vontade do legislador. A partir dos postulados positivistas, entendia-se que a função do Direito era meramente técnica, na qual para o emprego da lei não cabiam interpretações.

De acordo com Vanin (2015), o positivismo jurídico é uma corrente filosófica amplamente debatida, na qual os teóricos não comungam sobre os fatos sociais que definem o Direito (a vontade do legislador, a vontade do aplicador do direito, a eficácia social das normas) e sobre as características do sistema jurídico (se a finalidade do direito é a de garantir segurança jurídica e paz social ou é a importância da sanção e da coerção na definição do direito).

Dessa forma, o nascimento de novas teorias tem o condão de questionar os postulados formais do positivismo, a sistematização do conhecimento e as deduções lógicas do pensamento cartesiano. A partir da não aceitação dos métodos pré-ordenados, à luz das mudanças sociais, surgiram assim as teorias da argumentação jurídica.

A primeira teoria que questionou os postulados positivistas foi a do sociólogo Theodor Viehweg,(1979) com sua obra Tópica de Jurisprudência, publicada em 1953. Viehweg fez uma 
crítica ao método cartesiano de pensar a ciência, definindo sua teoria tópica como sendo "uma técnica de pensamento problemático". Para o autor, a utilização da tópica não está atrelada a um modelo específico de pensamento lógico-dedutivo, mas a um estilo de pensar as questões sociais mediante argumentos. Desse modo, a tópica refere-se ao ato de pensar e discutir os problemas sociais com a finalidade de desvendar caminhos possíveis.

O pensamento tópico, proposto por Viehweg(1979), contribuiu para a evolução do Direito Contemporâneo, uma vez que deu início ao movimento de não aceitação do Direito enquanto cartesiano positivado. Nesse movimento, podemos considerar que uma das formas ativas de interpretar o Direito se dá por meio dos estudos da linguagem jurídica. Sendo assim, na interface entre Linguagem e Direito, é possível analisar e interpretar a aplicabilidade das normas jurídicas enquanto prática social, a qual deve ser historicamente situada.

\section{LINGUAGEM E DIREITO ENQUANTO PRÁTICA SOCIAL}

A linguagem é considerada uma prática social (FAIRCLOUGH, 2003), na qual veiculamos informações, externamos sentimentos e agimos sobre o outro, logo o estudo do funcionalismo da linguagem, enquanto disciplina, articula-se com outras áreas do saber e contribui para a análise e interpretação.

O funcionalismo da linguagem tem por finalidade estudar a relação entre a estrutura gramatical das línguas e os diferentes contextos comunicativos em que elas são usadas, ou seja, busca-se compreender o aspecto funcional da língua em uso, na interação social, na relação entre linguagem e sociedade. Segundo Chouliaraki e Fairclough (1999), os estudos do funcionalismo da linguagem devem ser guiados pelas práticas sociais - maneiras recorrentes pelas quais agimos e interagimos no mundo - historicamente situadas, isso implica dizer que o fluxo cotidiano envolve ação, interação, relações sociais, pessoas (com crenças, valores, atitudes, histórias etc.).

Assim, os discursos, por exemplo, de médicos, jornalistas, da justiça, de professor, são mantidos por elementos linguísticos, por classes sociais e por elementos culturais e, por isso, devem ser analisados sob o viés crítico.

Por essa razão, partindo do entendimento de que os estudos da funcionalidade da linguagem contribuem de forma sistematizada para interpretação da aplicabilidade do Direito nas mais variadas práticas sociais, buscamos identificar e analisar um julgado acerca da indenização por dano moral decorrente de abandono afetivo. 


\section{Aporte teórico-metodológico}

Para a análise do texto jurídico da aplicação do Direito na prática social, utilizamos os estudos da funcionalidade da Linguagem, especificamente o aporte teórico metodológico da $A C D$, uma vez que, para essa teoria, a linguagem tem papel central para possíveis reflexões e para (re)construção das relações sociais.

$\mathrm{A} A C D$, por meio de seu aporte teórico e metodológico, deu suporte às análises, posto que, de acordo com Fairclough (2003), a ACD baseia-se na compreensão de como são produzidos e reproduzidos os discursos, devendo a pesquisa sempre partir de um problema social. Por essa razão, pretendemos identificar e analisar os modos como a relação Linguagem e Direito se materializam na prática social do abandono afetivo e como essa prática social é enfrentada pelos julgadores a partir da aplicabilidade das leis.

Este trabalho engaja-se na abordagem qualitativa, pois busca investigar, descrever e explicar os fenômenos sociais sem torná-los verdades absolutas. Segundo Godoy (1995), as diferentes áreas do conhecimento têm sido fortemente marcadas pela adoção e valorização da pesquisa qualitativa, pois essa abordagem não contempla apenas uma prática metodológica, mas um conjunto de práticas materiais e interpretativas que ampliam o olhar para o objeto em estudo, possibilitando o acesso a esse objeto sob diferentes ângulos, dando maior solidez à análise interpretativa, uma vez que propicia a compreensão de práticas sociais de forma contextualizada.

Nessa perspectiva, a abordagem qualitativa coaduna com a teoria da Análise Crítica do Discurso, pois, devido ao seu caráter interdisciplinar e sua vinculação à ciência social crítica, ambas buscam investigar e explicar os fenômenos sociais sem torná-los verdade absoluta.

\section{Caminhos metodológicos}

para a ACD, as práticas sociais moldam e são moldadas pelos discursos; dessa forma, Fairclough (2003) classifica o discurso em três significados distintos, a saber, o acional, o representacional e o identificacional. Para o autor, os três significados acontecem simultaneamente em uma prática discursiva, pois são dialéticos e sua distinção ou classificação é somente uma imposição metodológica.

Conforme Fairclough (2003), o significado acional é localizado no texto como modo de (inter)agir nos eventos sociais, tendo uma semelhança com a função relacional de Halliday (1994). Assim, cada prática social se apodera de um gênero discursivo particular, articulando estilos e discursos de modo estabilizado em cada momento sócio-histórico e cultural.

O significado identificacional está relacionado ao conceito de estilo. Estilos compõem aspectos discursivos de identidade (FAIRCLOUGH, 2003), ou seja, são alusivos à identificação 
de atores sociais em textos. Como o modo de identificação no discurso compreende efeitos constitutivos, Fairclough (2003) sugere que a identificação seja compreendida como um processo dialético.

O significado representacional destaca que os atores sociais agem sobre o mundo e interagem socialmente. Nesse processo, valores e identidades são representados de forma particular por intermédio de textos, que é qualquer amostra de linguagem em uso.

Especificamente neste trabalho, utilizamos o significado representacional do discurso, pois pretendemos identificar e analisar os modos como a relação Linguagem e Direito se materializam na prática social do abandono afetivo e como essa prática social é enfrentada pelos julgadores por meio da aplicabilidade das leis. Nessa direção, Fairclough (2001, p. 123) diz que a "representação é um processo de construção social de prática, incluindo a construção reflexiva de si - representações penetram em processos sociais e práticas e os moldam”. Essas representações podem aparecer nos textos por meio do sistema de transitividade proposto por Halliday (2004), constituído por três elementos principais: os processos, os participantes e as circunstâncias.

Os processos apresentam-se sob a forma de verbos; os participantes sob a forma de sujeitos e objetos; e as circunstâncias sob a forma dos diferentes tipos de elementos adverbiais.

Os processos podem ser classificados em: materiais, mentais, relacionais, comportamentais, existenciais e verbais, cada um representa uma ação, um evento, um estado, um processo, um sentimento e um existir. Os participantes são os elementos que se associam aos processos para indicar quem age, sente, existe e/ou fala. As circunstâncias são os elementos que exprimem modo, tempo, lugar e outros.

Segundo Fairclough (1989), os discursos representam aspectos do mundo, bem como contribuem para a intervenção sobre este. Desse modo, o significado representacional se relaciona ao conceito de discurso como modo de representação e está atrelado à ordem do discurso, indicando que diferentes discursos se fazem presentes em textos e representam diferentes perspectivas de mundo.

Nesse sentido, para fazer a análise das representações do discurso, o autor lança mão da categoria da interdiscursividade, que é uma das categorias de análise textualmente orientada. Por meio dessa categoria, é possível identificar os diferentes discursos e a forma como são articulados em um texto (CHOULIARAKI; FAIRCLOUGH, 1999; FAIRCLOUGH, 2003). Nesse viés, tanto os atores sociais como os discursos podem complementar-se, cooperando uns com os outros, competindo entre si ou dominando uns aos outros.

Assim, a categoria da interdiscursividade faz parte da análise discursiva do artigo e mapeará quais discursos estão articulados nos enunciados das decisões judiciais. Essa categoria mostra-se importante, visto que proporciona subsídio para a compreensão dos discursos jurídicos e como eles dialogam com outros textos. 
Em relação ao corpus do artigo, recortamos um trecho de um recurso de apelação do Tribunal de Justiça do Rio Grande do Sul, ${ }^{1}$ o qual versa sobre a possibilidade ou não de reparação por dano moral decorrente de abandono afetivo.

\section{ANÁlise}

Trata-se de um recurso de apelação do Tribunal de Justiça do Rio Grande do Sul. O pedido é de reparação civil por dano moral, em razão de abandono afetivo. O recurso fora julgado improcedente, pois, segundo os magistrados, o abandono afetivo nada tem a ver com direito da personalidade, com os direitos fundamentais ou com qualquer garantia constitucional, constituindo mera pretensão indenizatória, com caráter econômico, estando sujeita ao lapso prescricional, logo é um recurso desprovido.

Em seus estudos sobre a teoria da Linguística Sistêmica Funcional, Halliday (2004) aclara que a língua exerce uma função social, produz significados e ainda constrói potenciais de significação e com isso as escolhas das palavras constituem identidades, representações acerca do que se fala, sendo possível desvelar quem o diz, o que, a quem e em que determinada circunstância, através da análise dos processos e dos seus participantes. Nessa mesma esteira, a escolha lexical (significado das palavras) tem uma importância nos estudos discursivos, pois torna produtiva a análise de determinadas palavras e, ainda, é produtiva para observar as representações (FAIRCLOUGH, 2016).

Feita essa breve contextualização, iniciamos nossa análise observando as escolhas lexicais presentes no documento jurídico escolhido por nós.

Sob a égide da Análise Crítica do Discurso, o processo material indenização no Julgado é empregado para referir-se ao ato a ser praticado por uma pessoa em favor de outra. Além disso, podemos afirmar que processos são, gramaticalmente, itens lexicais que expressam uma ação, um evento, um estado, um processo, um sentimento, um existir.

Assim, o processo indenizar refere-se à compensação devida a alguém de maneira a anular ou reduzir um dano, geralmente, de natureza moral ou material, originado por descumprimento total, ou cumprimento deficiente de uma obrigação, ou através da violação de um direito.

Logo, o participante que, no julgado, encontra-se oculto/indeterminado, refere-se ao sujeito da ação de indenizar. Participantes são os elementos que se associam aos Processos para indicar quem age, sente, existe, fala, ou encontra-se em dado estado. O participante, sujeito da oração, recebe essa classificação gramatical em razão de sua importância no texto. Quando o participante/sujeito aparece na oração é chamado de determinado e, quando está escondido, de indeterminado.

$\overline{{ }^{1} \text { Vide anexo. }}$ 
Na mesma direção, o julgado traz, também, a circunstância da oração, que, no texto, se faz representado pelo substantivo masculino "abandono". As circunstâncias são os elementos que exprimem modo, tempo, lugar, entre outros, acompanha um fato ou uma situação e que lhes é essencial à natureza.

Em razão disso, percebe-se um contrassenso entre a pretensão do autor, que pediu indenização em razão do abandono afetivo e a decisão dos magistrados, vez que os elementos que compõem o dever de indenizar se fazem presentes no texto, mas a decisão se fez contrária ao pedido.

O processo de indenizar é oriundo do termo responsabilidade, utilizado em várias áreas das ciências, possuindo significados diversos. No âmbito informal, a expressão responsabilidade pode ser sinônimo de cuidado. Já no plano jurídico, revela a obrigação de todos pelos atos ilícitos que praticam.

Etimologicamente, o termo responsabilidade deriva do vocábulo respondere, spondeo e possui ligação direta com o conceito de obrigação de natureza contratual, originária do direito romano. Inicialmente, não se vinculava à ideia de compensação por um prejuízo causado, mas a concepção romana de responsabilidade.

Dessa forma, o tema responsabilidade integra o ramo do direito obrigacional, relativo ao dever, segundo o qual a conduta humana está vinculada ao seu fim, econômico ou social, e, na eventualidade do descumprimento da obrigação, surge, então, o dever de compensar o dano causado. A responsabilidade nada mais é do que o dever de indenizar o dano, isto é, quando um fato causa um dano, este dano, por regra, deve ser reparado (DINIZ, 1998).

De acordo com Diniz (2013), existem elementos que compõem a estrutura jurídica do dever de indenizar, são eles: ação ou omissão; nexo de causalidade e dano (moral ou patrimonial). Por ação, deve-se entender a conduta do agente, do participante, uma ação que pode ser omissiva e ou comissiva, de forma a causar um dano a outrem. O nexo de causalidade é o elo entre a conduta e o resultado. Já o dano é o resultado da conduta do agente, pode ser moral (quando atinge a individualidade humana) ou patrimonial (quando atinge bens materiais).

O dano a ser reparado pode ser material, moral ou estético, de acordo com sua natureza. A reparação deve ser feita primeiramente a fim de se restabelecer o status quo, devendo ser proporcional ao dano, podendo extrapolar a capacidade monetária daquele que o dano causou. Todavia existem os direitos de personalidade, fundamentais aos seres humanos. Esses direitos são dotados de suas características peculiares e ensejam indenização, caso desrespeitados.

No processo, embora o julgado tenha apresentado os elementos jurídicos que compõem o dever de reparação/indenização, (quem julgou) julgou improcedente o mérito da questão.

A interdiscursividade presente nos enunciados remete a um contrassenso entre a decisão e os direitos da personalidade, que são direitos fundamentais do ser humano, em geral, 
são garantias que as pessoas têm em relação a diversos aspectos de si próprias, proteções que visam à dignidade da pessoa humana.

Os direitos da personalidade surgiram na época das revoluções e são atos afirmativos das liberdades individuais, resguardando a dignidade humana do indivíduo perante outros e perante o Estado. São direitos natos, intransmissíveis, irrenunciáveis, imprescritíveis, impenhoráveis, vitalícios e se opõem a erga omnes. Dentre esses Direitos, podemos citar: a honra, a intimidade, a privacidade, a imagem, a voz, o nome, pseudônimo e apelido; o sigilo industrial, o sigilo profissional, entre outros (BRASIL, 1988).

De maneira geral, os direitos da personalidade são direitos fundamentais dos seres humanos, constitucionalmente tutelados, e sua violação é passível de indenização, mais comumente na esfera do dano moral, sendo irrenunciáveis, intransferíveis e imprescritíveis.

O texto do julgado também remete a um desalinhamento com o direito de família, especificamente, sobre os direitos e deveres do poder familiar, do qual se extrai a ideia de dever dos pais, em igualdade de condições, garantir aos filhos o sustento, a guarda e a educação, em níveis afetivo, familiar e social.

Nota-se que o poder familiar é instituído no interesse dos filhos e da família, não em proveito dos pais, em especial, em atenção ao princípio constitucional da paternidade responsável, estabelecido no artigo 226, $\$ 7^{\circ}$, da Constituição Federal. Para Gonçalves (2012, p. 360), "poder familiar é o conjunto de direitos e deveres atribuídos aos pais, no tocante à pessoa e aos bens dos filhos menores".

Assim, poder familiar faz parte do estado das pessoas e, por isso, não pode ser alienado nem renunciado, delegado ou substabelecido. É, portanto, irrenunciável, incompatível com a transação, é indelegável, não podendo os pais renunciá-lo, nem o transferir a outrem, já que o poder familiar é múnus público, pois é o Estado que fixa as normas para o seu exercício.

A norma jurídica atribui aos pais o poder familiar e diz que, na falta do cumprimento desses deveres, devem os pais indenizarem os filhos pelo abandono, uma vez que o art. 229 da Constituição Federal impõe aos pais o dever de assistir, criar e educar os filhos, tratando-se de uma obrigação e não de uma discricionariedade, não sendo possível sua renúncia.

Contudo, necessário se faz frisar que o dever de assistência, oriundo do poder familiar, não se resume à matéria consubstanciada em auxílio financeiro, vertente patrimonial, mas, sobretudo da relação afetiva, assistência moral, psicológica, educacional, motivacional dos filhos.

Em consonância com o princípio constitucional da dignidade da pessoa humana, o poder familiar é caracterizado por ser intransferível, irrenunciável e imprescritível, ou seja, é uma obrigação legal e não uma faculdade dos pais para com os filhos.

No Direito Civil, a prescrição é conceituada como a perda da pretensão do titular de um direito que não o exerceu em determinado lapso temporal. Desse modo, no mínimo, há uma 
incongruência nas falas dos magistrados e a decisão proferida por eles, logo há um possível desalinhamento entre a lei e o caso concreto.

Em relação ao momento em que ocorreu a prescrição do direito de reparação por abandono afetivo, o julgado deixa de forma vaga e abstrata, surgindo assim algumas indagações, por exemplo: Se o poder familiar é imprescritível, como poderia sua reparação prescrever? Em que momento iniciou o direito a reparação? Ou seja, em que momento ocorreu o abandono? Esses questionamentos têm por objetivo indagar acerca da insegurança jurídica dos julgados, uma vez que o prazo prescricional tem início não da lesão ao direito subjetivo, mas do conhecimento da lesão.

Nesse sentido, deve ser considerada a teoria da actio nata, segundo a qual "o prazo prescricional tem início a partir da data em que o credor pode demandar judicialmente a satisfação do crédito", por analogia, a referida teoria também poderia ser aplicada no caso em análise.

De acordo com o Julgado, para reparação de ato ilícito, o prazo para ajuizamento da ação prescreve em três anos, nos termos do inciso V, \$ 30 do artigo 206 do Código Civil, entretanto isso fora estipulado em prol da operabilidade, a fim de facilitar a instrumentalidade dos atos processuais, conforme o caso em análise.

Seguindo tal orientação, os prazos de prescrição são associados às ações condenatórias, caso das demandas relativas à responsabilidade civil, seja ela contratual ou extracontratual, não mantendo relação com o direito de família.

Dito isso, a prescrição aduzida no julgado parece não sustentar que os direitos da personalidade são imprescritíveis e devem ser reparados.

Portanto, a análise do Julgado em tela corrobora as palavras de Colares (2014), que diz que o direito faz ancoragem no eterno, permanecendo idêntico, já a linguagem é dinâmica, inquieta, no fluxo da práxis está sempre em movimento, historicamente situada diferencia de si mesma a cada interpretação, numa dialética de construção de sentidos, moldando-se a cada situação de uso.

\section{À GUISA DE CONCLUSÃo}

De acordo com a Constituição Federal de 1988, as demandas que envolvem direito da personalidade são irrenunciáveis, intransferíveis e imprescritíveis.

No entanto, o julgado analisado não admitiu a possibilidade de indenização por dano moral decorrente de abandono afetivo, desse modo, parece haver um contrassenso entre o texto analisado e os direitos da personalidade. 
Ante a análise gramatical, textual do julgado em tela, percebeu-se a incongruência da decisão do mérito em questão, pois no caso concreto faziam-se presentes os elementos que caracterizam o dano e o dever repará-lo.

A decisão também se mostrou em desarmonia com os princípios da dignidade da pessoa humana, uma vez que, constitucionalmente, são intransferíveis, irrenunciáveis e imprescritíveis.

Outrossim, diante da feição subjetiva do julgado em apreço, que não precisou qual o termo a quo para o início do prazo prescricional de indenização por dano moral decorrente de abandono afetivo, entende-se que os danos são continuados, não cessam, mesmo em se tratando de pessoa com idade avançada, em outras palavras, o prejuízo é de trato sucessivo, atinge a honra do filho, fere a dignidade da pessoa humana e coloca em xeque os deveres familiares, que são, acima de tudo, imprescritíveis.

Portanto, o tema indenização por dano moral, decorrente de abandono afetivo, demonstrou o quão involuído são as decisões jurídicas, não só no seu conteúdo, mas também na verificação das peculiaridades da existência ou não da suposta pretensão, confirmando, assim, o positivismo jurídico das decisões judiciais.

\section{REFERÊNCIAS}

BOBBIO, Norberto. O positivismo jurídico: lições de filosofia do direito. São Paulo: Ícone, 1995. BRASIL. Constituição da República Federativa do Brasil de 1988. Disponível em: http://www. planalto.gov.br/ccivil_03/constituicao/constituicaocompilado.htm Acesso em: 15 maio 2018.

BRASIL. Estatuto da Criança e do Adolescente. Lei nº 8.069 de 13 de julho de 1990. Disponível em: http://www.mpdft.mp.br/portal/pdf/unidades/promotorias/pdij/Legislacao\%20e\%20 Jurisprudencia/ECA_comentado.pdf. Acesso em: 2 jun. 2018.

CHOULIARAKI, L.; FAIRGLOUGH, N. Discourse in Late Modernity: Rethinking Critical Discourse Analysis. Edinburgh Univesity Press, 1999.

COLARES, Virgínia. Análise Crítica do Discurso Jurídico (ACDJ): o caso Genelva e a (im) procedência da mudança de nome. ReVEL, v. 12, n. 23, 2014. Disponível em: http://revel.inf. br/files/f525d6e5fco6a7bo3d654d92f278ae97.pdf. Acesso em: 25 jun. 2021.

COLARES, Virgínia. Linguagem E Direito No Brasil. 2010. Disponível em: https://webcache. googleusercontent.com/search?q=cache:4BjfHw_9qYAJ:https://dialnet.unirioja.es/descarga/ articulo/3199551.pdf+\&cd=1\&hl=pt-BR\&ct=clnk\&gl=br Acesso em: 25 jun. 2021.

DINIZ, Maria Helena. Curso de Direito Civil Brasileiro. 12. ed. São Paulo: Saraiva, 1998. 
DINIZ, Maria Helena. Curso de Direito Civil Brasileiro. 27. ed. São Paulo: Saraiva, 2013. v. 7. FAIRCLOUGH, N. Discurso e Mudança Social. Brasília: Editora Universidade de Brasília, 2001. FAIRCLOUGH, N. Analysing discourse. Routledge: Taylor; Francis Group: London and New York, 2003.

FAIRCLOUGH, N. Language and Power. London: Longman, 1989.

FAIRCLOUGH, N. Discurso e Mudança Social. 2. ed. Brasília: Editora Universidade de Brasília, 2016. GODOY, A. S. Introdução à Pesquisa Qualitativa e suas Possibilidades. RAE-Revista de Administração de Empresas, v. 35, n. 2, mar.-abr., p. 57-63, 1995.

GONÇALVES, Carlos Roberto. Direito Civil Brasileiro - Direito de Família. São Paulo. Editora Saraiva, 2012.

HALLIDAY, M. A. An introduction to Functional Grammar. 2. ed. London: Edward Arnold, 1994. HALLIDAY, M. A.; MATTHIESSEN, C. M. I. M. An introduction to Functional Grammar. 3. ed. London: Hodder Arnold, 2004.

KELSEN, Hans. Teoria Pura do Direito. Tradução de João Baptista Machado. 4. ed. Coimbra: Armênio Amado Editor, 1979.

VIEHWEG, Theodor. Tópica e Jurisprudência. Tradução de Tércio Sampaio Ferraz Jr. Brasília: Departamento de Imprensa Nacional, 1979.

\section{Anexo}

\section{RELATÓRIO \\ des. Sérgio Fernando de Vasconcellos Chaves (PRESIDENTE E RELATOR)}

Trata-se da irresignação de LÍGIA M. B., contra a r. sentença que julgou extinta a ação, com fundamento no art. 269, inc. IV, do CPC, nos autos da ação indenizatória que move contra TANDREDO S. B.

Sustenta a recorrente que a sua pretensão nitidamente afeta os direitos da sua personalidade, sendo uma das suas principais características a imprescritibilidade. Diz que os prejuízos morais e sentimentais causados repercutem durante toda a sua vida, sendo impossível, precisar, sem amparo probatório, quando o abandono teria sido constatado para 
iniciar a contagem prescricional. Assevera que a indenização servirá para compensar os danos causados, bem como para punir o recorrido do abandono, pois este foi praticado de forma dolosa, uma vez que o mesmo sempre soube que era seu pai biológico. Assegura que ao declarar prematuramente a prescrição foi mitigada a instrução probatória, a qual poderia contribuir para um deslinde distinto a demanda. Aduz que deve ser considerada a teoria da actio nata, segundo a qual "o prazo prescricional tem início a partir da data em que o credor pode demandar judicialmente a satisfação do crédito". Afirma que o abandono afetivo tem raiz psicológica e que para alguns pode restar configurado nos primeiros dias de ausência, para outros anos após. Refere que a demanda, por ser complexa, enseja a instrução probatória, sob pena de ofensa do princípio da inafastabilidade do poder judiciário, consoante dispõe o art. $5^{\circ}, \mathrm{XXXV}$, da Constituição Federal. Pretende seja reconhecida a imprescritibilidade da pretensão ligada à proteção dos seus direitos personalíssimos ou, caso não seja esse o entendimento, seja postergada a análise da prescrição para após a dilação probatória. Pede o provimento do recurso.

Intimado, o recorrido apresentou contra-razões pugnando pela manutenção da sentença.

Com vista aos autos, a douta Procuradoria de Justiça lançou parecer opinando pelo conhecimento e desprovimento do recurso.

Foi observado o disposto no art. 551, $\$ 2^{\circ}$ do CPC.

É o relatório.

\section{Votos}

\section{des. Sérgio Fernando de Vasconcellos Chaves (PRESIDENTE E RELATOR)}

Estou desacolhendo o pleito recursal.

Com efeito, observo que a recorrente nasceu em 19/05/1952 (fl. 16), tendo completado a maioridade em 1973, de acordo com o Código Civil vigente na época, o qual estabelecia a maioridade a partir dos 21 anos de idade. Considerando-se que a ação de indenização por dano moral decorrente de abandono afetivo foi proposta em 28 de fevereiro de 2013 , portanto após o decurso de lapso de tempo muito superior ao prazo legal de três anos contados da vigência do Código Civil de 2002, é imperioso reconhecer a prescrição da ação, consoante expressa previsão do art. 206, $\$ 3^{\circ}$, inc. $V$, do $C C B / 2002$. 
Aliás, a pretensão indenizatória também já estava prescrita sob a égide da legislação civil de 1916... Observo, pois, que a autora nasceu em 19 de maio de 1952, tendo completado a maioridade civil em 19 de dezembro de 1973, sendo este o termo a quo do prazo prescricional, e o Código Civil de 2002, que entrou em vigor em 10 de janeiro de 2003, estabeleceu a redução do prazo prescricional para as ações de reparação civil, reduzindo-a de vinte anos para três anos, tendo incidência, então, a regra de transição posta no art. 2.028 do $\mathrm{CCB} / 2002$.

No caso em exame, como a autora completou a maioridade na vigência do Código Civil de 1916, e como já havia transcorrido mais da metade do prazo prescricional até a data da entrada em vigor do Código Civil de 2002 , então o prazo prescricional a ser considerando no caso sub judice é de 20 anos, aplicando-se a disposição do Código Civil de 1916.

Sendo assim, a ação indenizatória poderia ter sido proposta pela autora até o dia 19 de maior de 1993, mas somente foi ajuizada em 2013, quando seu direito já havia sido fulminado há muito tempo pelo transcurso do prazo de prescrição.

Destaco, finalmente, que o pedido de reparação civil por dano moral, em razão do abandono afetivo, nada tem a ver com direito de personalidade, com direitos fundamentais ou com qualquer garantia constitucional, constituindo mera pretensão indenizatória, com caráter estritamente econômico, estando sujeita ao lapso prescricional, como todo e qualquer pleito reparatório civil.

ISTO POSTO, nego provimento ao recurso.

DES. ${ }^{a}$ LISELENA SCHIFINO ROBLES RIBEIRO (REVISORA) - De acordo com o(a) Relator(a). DES. ${ }^{\text {a }}$ SANDRA BRISOLARA MEDEIROS - De acordo com o(a) Relator(a). DES. SÉRGIO FERNANDO DE VASCONCELLOS CHAVES - Presidente - Apelação Cível n ${ }^{\circ} 70056484413$, Comarca de Santo Ângelo: “NEGARAM PROVIMENTO. UNÂNIME”. Julgador(a) de $1^{\circ} \mathrm{Grau}$ : NINA ROSA ANDRES

Recebido para publicação em: 4 set. 2021. Aceito para publicação em: 26 out. 2021. 